\title{
Cystercercus Larva in the Anterior Chamber of the Eye of a 7- year-old Nigerian Girl
}

\author{
C $O$ Bekibele MD, MSc $^{1}$, C A Okolo MBBS, FMCPath ${ }^{2}$, Adebanjo MBBS ${ }^{1}$
}

${ }^{1}$ Department of Ophthalmology, University College Hospital, Ibadan and College of Medicine, University of Ibadan, Nigeria

${ }^{2}$ Department of Pathology, University College Hospital, Ibadan and College of Medicine, University of Ibadan, Nigeria

\section{SUMMARY}

The case of a 7 year old Nigerian girl with features of traumatic uveitis which was later found to have anterior chamber cestode larva infestation is presented. Though uncommon, ocular cestode larva infestation should be considered when children present with features of ocular inflammation.

\section{INTRODUCTION}

Cestoda is a class of parasitic worms called tape worms. They belong to the phylum plathyhelminthes. They live in the gastrointestinal tracts (GIT) of vertebrates as adult worms and sometimes in the body tissues of many types of animals in the immature or juvenile form. Infection of humans occurs following ingestion of the ova in under- processed meat of pigs, cats, sheep, dogs (T. solium, Echinococcus), cows (T. saginata), rodents (Hymenolepsis), and fish (Diphyllobothrium spp), and from fleas on dogs and cats (D. craninum). ${ }^{1}$

The larva migrates to various parts of the body through the blood vessels and lymphatic circulation (after digestion of its outer covering in the GIT and release into the blood stream). It may arrive in the eye and cause ocular infestation or cyst formation. The subretinal space is said to be the most common site for cysticercosis infestation while involvement of the anterior chamber is said to be unusual. ${ }^{2,3}$

Symptoms of ocular involvement with cestode infesta-tion depend on the area involved and may include recurrent conjunctivitis, subconjuctival swelling, defective vision, and proptosis. ${ }^{4}$

We present the case of a 7-year-old Nigerian girl who was seen with features of traumatic uveitis but was later found to have anterior chamber cestode larva infestation.

\section{CASE REPORT}

A 7-year-old Nigerian girl of Efik ethnicity presented at the eye clinic of the University College Hospital, Ibadan having been referred from a private hospital with a one-week history of pain, redness and reduced vision in the left eye. There was background history of minor trauma to the eye when she was hit in the eye with the end of a cloth by an older sibling. She was given betamethasone and chloramphenicol eye drops by the referral hospital which she used with no significant improvement. Ocular examination revealed a vision of $6 / 6$ OD and hand movement OS. The right eye appeared normal clinically while the left had blepharospasm, ciliary flush and a slightly hazy cornea. There were stromal oedema and mutton fat keratic precipitates on the endothelium. The anterior chamber appeared deep and contained whitish material which was thought to be soft lens matter from a break in anterior lens capsule. The pupil appeared irregular and poorly reactive. There was no further view of intraocular contents. Intra-ocular pressure was $26 \mathrm{~mm} \mathrm{Hg}$. An ocular ultrasound examination revealed no vitritis and no additional information. Systemic examination was essentially normal. An assessment of traumatic/ phacoanaphylactic uveitis was made.

The patient was commenced on dexamethasone, timolol and atropine eye drops. Subsequent examination about two weeks later showed that the whole anterior chamber was filled with a cystic whitish mass which was thought to be an intumescent cataract or anterior subluxated lens. Examination under anaesthesia with possible surgery to remove the offending anterior chamber material was planned. Following general anaesthesia and under high magnification, the anterior chamber (AC) material was seen to be motile, and occupied the entire AC (figure 1). A superior paracentesis incision was made and the cystic mass was completely extracted from the AC with the aid of forceps (after a break occurred in the protruding wall during the attempt to widen the wound).

The anterior chamber and ocular contents however appeared normal. Histology of the removed mass revealed a tiny fragment of grayish white tissue whose section showed a cestode larva having a cuticle with an invaginated protoscolex and integument (figures 2-4.) These features were suggestive of eucestoda infestation with propagation of the cysticercus in the eye. Stool examination for microscopy of ova and parasite were however negative.

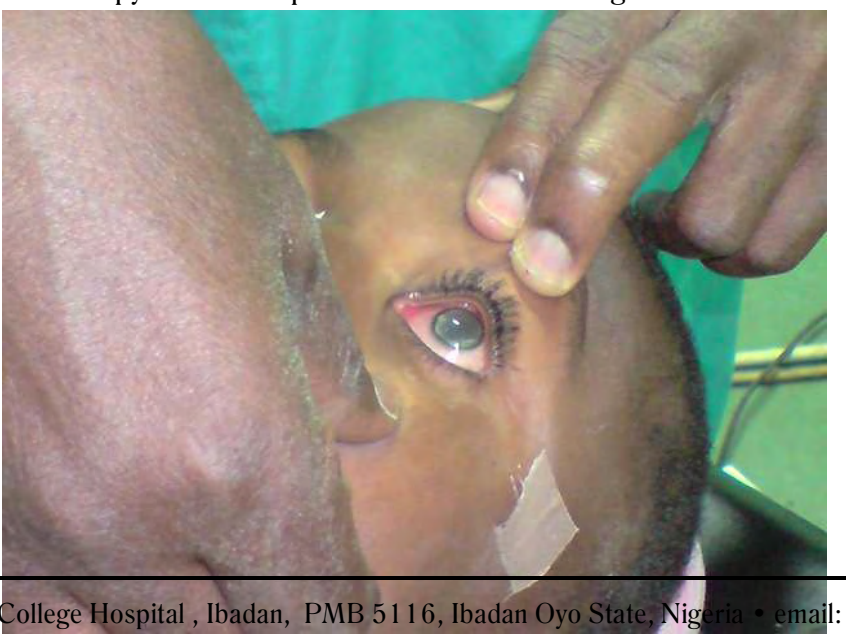

Figure 1. Cestode cysticercus in anterior chamber of eye of 7 year old girl.
*Correspondence: Dr. CO Bekibele, Department of Ophthalmology, University cob150@yaho.com 


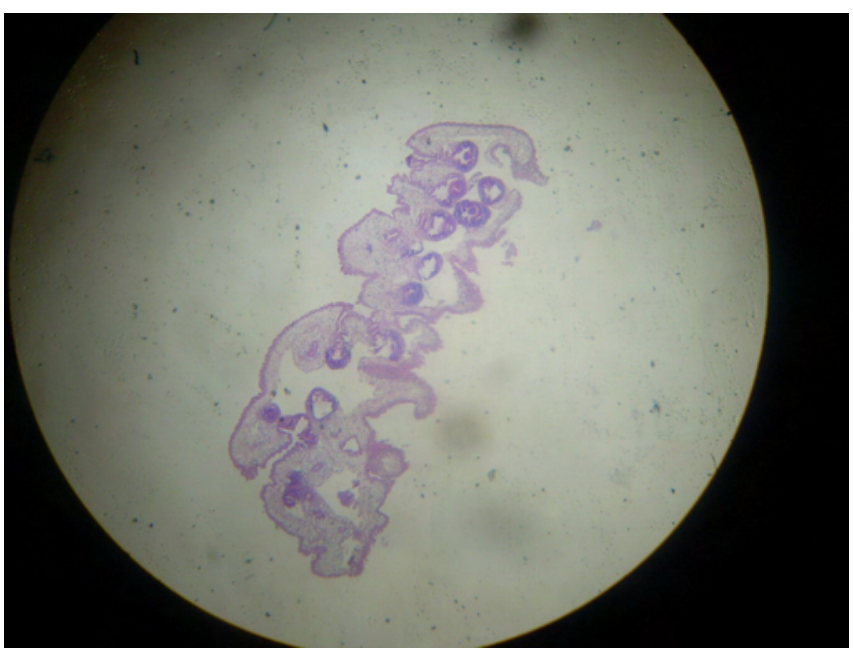

Figure 2. Microscopic section of the cestode worm after surgical removal from the anterior chamber of eye $\mathrm{H} \& \mathrm{E}$ X 400 .

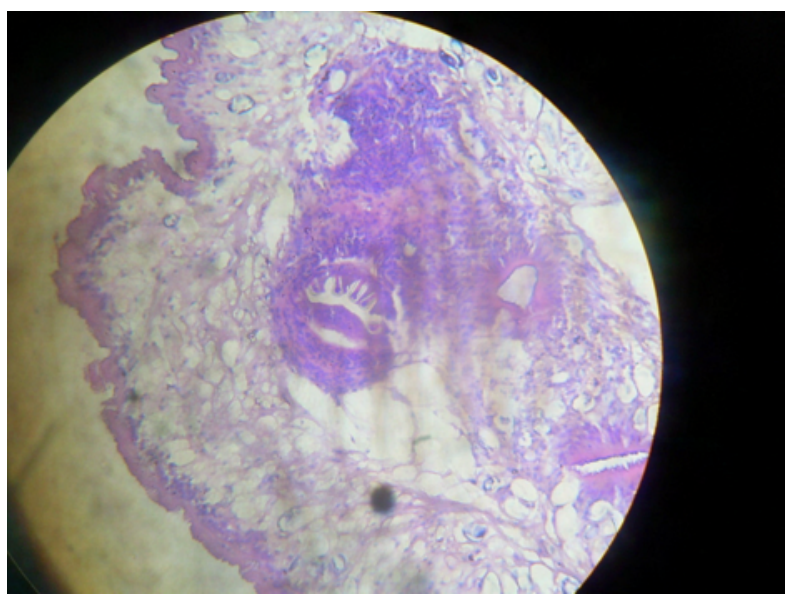

Figure 3. Higher power section of the cestode worm showing the primitive form of the invaginated sucker in the centre

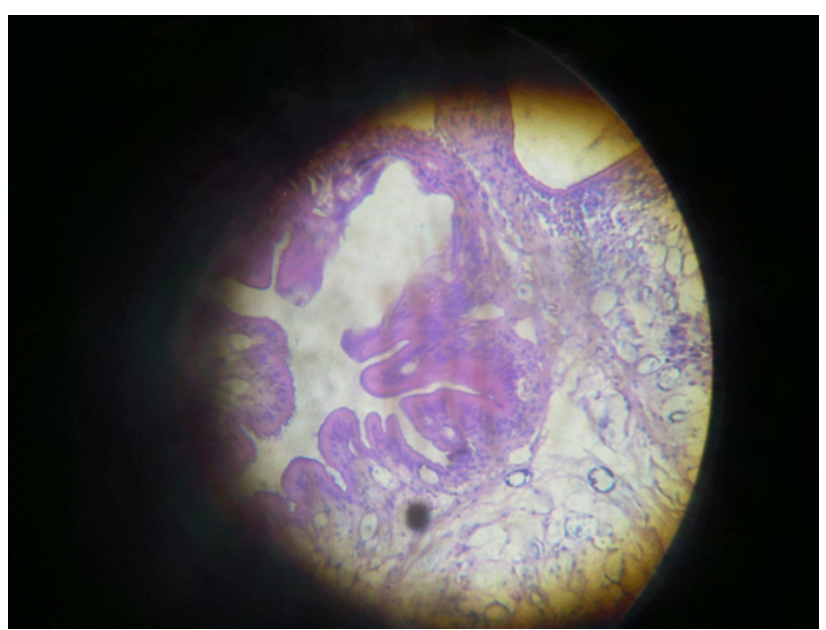

Figure 4. Higher power section of the cestode worm showing the villi of the sucker.
Post operatively, the patient was treated empirically with oral Albendazole, topical antibiotic drops and steroids. The post operative vision had improved to $6 / 6$ when she was last seen eight weeks after surgery.

\section{DISCUSSION}

Cestode infestation in the paediatric age group is not uncommon due to children's often unhygienic habits. ${ }^{[1]}$ However, the case in view was initially missed due to preceding history of minor trauma and presentation with features suggestive of uveitis. The presence of corneal oedema did not allow the accurate visualization of the cestode cyst in the AC at presentation. However following the use of topical steroids and intraocular pressure (IOP) lowering drugs to reduce inflammation and IOP, the motile cestode cysticercus was visible under high magnification, after the child had been subjected to general anaesthesia. Many cestode infestations are asymptomatic. However, once symptoms occur, they are usually vague gastrointestinal complaints such as abdominal pain, anorexia, weight loss, or malaise.

When humans are the primary hosts, the adult cestode is limited to the intestinal tract. When humans are the intermediate hosts, the larvae are found within the tissues, and migrate through the different organ systems.

Some of the more serious infestations result in symptoms from mass effects on vital organs, inflammatory responses, nutritional deficiencies, and the potential of fatal anaphylaxis. Infestation of the eye is not common, but when it does occur, it may present with signs of inflammation and visual impairment. The form of the cestode which usually affects the eye is the metacestode (cysticercus) which usually is encysted with a short segment with integument and invaginated poorly developed protoscolex.

The cysticerci that develop with $T$. solium infestations can be found anywhere in the body, but they mainly occur in the central nervous system and skeletal muscles, causing local inflammatory responses and mass effects from the cystic growth.

It is not clear what the source of the infestation was in this case, although the parents gave a history of the child ingesting poorly prepared dog and pork meat. A stool microscopy for ova and parasite examination done was negative for evidence of adult tapeworm in the patient suggesting intermediate rather than primary host infestation. Both T. solium (pork and dog) and Echinococcus (dog) have been known to show both primary and intermediate infestation of humans. ${ }^{1}$ However the pathological findings in this case were more in keeping with those of $\mathrm{T}$. solium infestation, for which the patient was given oral albendazole post operatively.

Inadvertent rupture of the larva wall during removal from AC may be associated with prolonged pre-op inflammation, ${ }^{5}$ but the use of topical steroids pre and post operatively ensured that by eight weeks when patient was last seen, all evidence of inflammation had disappeared from the eye and presenting vision had improved to $6 / 6$ in the affected eye.

\section{CONCLUSION}

The case of a 7-year-old Nigerian girl with features of traumatic 
uveitis which was later found to have anterior chamber cestode cysticercus infestation is presented. This suggests that cestode infestation should be considered along with other causes of inflammation when children present with ocular inflammation.

\section{REFERENCES}

1. Irizarry L, Phan P. Tapeworm infestation eMedicine 2009. WWW. emedicine.medscape.com

2. Bartholomew RS. Sub retinal cystercercosis. Am J Ophthalmol 1975; 79:670-3.

3. Beri S, Vajpayee RB, Dhingra N, Ghose S. Managing anterior segment cystercercosis by viscoexpression: a new surgical technique. Arch Ophthalmol 1994; 112: 1279-80.

4. David S, Mathai E. Ocular cystercercosis: a review of 25 cases. J Assoc Physicians India. 2000; 48: 704-7.

5. Kai S, Vanathi M, Vengayil S, Panda A. Viscoexpression of large free floating cisticercus cyst from the anterior chamber of the eye by double incision technique. Indian J Med Microbiology $2008 ; 26: 277-8$. 